NERSON, H.; GOVERS, A. Salt priming of muskmelon seeds for low-temperature germination. Scientia Horticulturae, v. 2, p. 8591, 1986.

NERSON, H.; CANTLIFFE, D.J.; PARIS, H.S.; KARCHI, Z. Low temperature germination of birdnest-type muskmelons. HortiScience, v. 17, p. 639-640, 1982.

OLUOCH, M.O.; WELBAUM, G.E. Effect of postharvest washing and post-storage priming on viability and vigour of six-year-old muskmelon (Cucumis melo L.) seeds from eight stages of development. Seed Science and Technology, v. 24, p. 195-209, 1996a.

OLUOCH, M.O.; WELBAUM, G.E. Viability and vigor of osmotically primed muskmelon seeds after nine years of storage. Journal of the American Society for Horticultural Science, v. 121, p. 408413, $1996 \mathrm{~b}$.

OSBURN, R.M.; SCHROTH, M.N. Effect of osmopriming sugar beet seed on germination rate and incidence of Pythium ultimum damping-off. Plant Disease, v. 73, p. 21-24, 1989.
PARERA, C.A.; CANTLIFFE, D.J. Presowing seed priming. Horticultural Reviews, v. 16, p. 109139, 1994.

PASSAM, H.C.; KARAVITES, P.I.; PAPANDREOU, A.A.; THANOS, C.A.; GEORGHIOU, K. Osmoconditioning of seeds in relation to growth and fruit yield of aubergine, pepper, cucumber and melon in unheated greenhouse cultivation. Scientia Horticulturae, v. 38, p. 217-216, 1989

PILL, W.G.; FRETT, J.J.; MORNEAU, D.C. Germination and seedling emergence of primed tomato and asparagus seeds under adverse conditions. HortScience, v. 26, n. 9, p. 1160-1162, 1991

RUSH, C.M. Comparison of seed priming techniques with regard to seedling emergence and Pythium damping-off in sugar beet Phytopathology, v. 81, n. 8, p. 878-882, 1991.

SHANNON, M.C; BOHN, G.W.; MCCREIGHT, J.D. Salt tolerance among muskmelon genotypes during seed emergence and seedling growth. HortScience, v. 19, p. 828-830, 1984.
SOUZA, V.F; RODRIGUES, B.H.N.; SOBRINHO, C.A.; COELHO, E.F.; VIANA, F.M.P.; SILVA, P.H.S. Cultivo do meloeiro sob fertirrigação por gotejamento no meio-norte do Brasil. Teresina: Embrapa Meio-Norte, 1999. 68 p. (Embrapa Meio-Norte. Circular Técnica, 21).

TAYLOR, A.G.; HADAR, Y.; NORTON, J.M.; KHAN, A.A.; HARMAN, G.E. Influence of presowing seed treatments of table beets on the susceptibility to damping-off caused by Pythium. Journal of the American Society for Horticultural Science, v. 110, n. 4, p. 516-519, 1985.

WELBAUM, G.E.; BRADFORD, K.J. Water relations of seed development and germination in muskmelon (Cucumis melo L.). VI. Influence of priming on germination responses to temperature and water potential during seed development Journal of Experimental Botany, v. 42, p. 393 399, 1991.

YEOUNG, Y.R.; WILSON JR.; D.O.; MURRAY, G.A. Germination performance and loss of lateembryogenesis-abundant (LEA) proteins during muskmelon seed priming. Seed Science and Technology, v. 24, p. 429-439, 1996.

HENZ, G.P. Doenças da mandioquinha-salsa e sua situação atual no Brasil. Horticultura Brasileira, Brasília, v. 20, n. 2, p. 135-144, junho 2.002.

\title{
Doenças da mandioquinha-salsa e sua situação atual no Brasil
}

\author{
Gilmar P. Henz \\ Embrapa Hortaliças, C. Postal 218, 70.359-970 Brasília-DF; E-mail: gilmar@cnph.embrapa.br
}

\section{RESUMO}

Este artigo tem como objetivo principal relatar as doenças registradas para a mandioquinha-salsa até a data presente e descrever sua situação atual no País. Na literatura, foram registrados para a cultura 27 gêneros de fungos, três de bactérias, doze de nematóides e cinco espécies de vírus. Destes, já foram relatados no Brasil treze fungos, e todos nematóides e bactérias, enquanto nenhum vírus foi oficialmente registrado, embora já tenham sido observadas plantas com sintomas típicos de viroses a campo. A maior parte dos registros estão na forma de resumos, capítulos de livros ou publicações genéricas, desprovidos de uma série de dados relevantes, como provas de patogenicidade, importância da doença, perdas, identificação mais acurada, entre outras. A cultura da mandioquinha-salsa ainda é tida como rústica, sendo poucas as doenças consideradas limitantes. O nematóide das galhas (Meloidogyne spp.) e a podridão-mole pós-colheita causada por Erwinia spp. são os principais problemas atualmente, e causam perdas significativas. Também ocorrem com muita frequência manchas foliares causadas por Septoria, Cercospora e Xanthomonas campestris pv. arracaciae, e em algumas regiões podridão de plantas a campo causadas por Sclerotinia sclerotiorum e Sclerotium rolfsii. Como não existe nenhum produto químico oficialmente registrado para a mandioquinha-salsa no Ministério da Agricultura, Pecuária e Abastecimento, as medidas de controle passíveis de recomendação incluem ações preventivas, como o uso de material propagativo sadio (preferencialmente mudas pré-enraizadas de origem conhecida), a adoção de rotação de culturas, a eliminação de plantas ou partes doentes, e a adubação e a irrigação adequadas. O estudo sistematizado das doenças e o registro cuidadoso de surtos ou novas enfermidades para a cultura são importantes para subsidiar futuras medidas de controle.

Palavras-chave: Arracacia xanthorrhiza, fungos, bactérias, nematóides, vírus.
ABSTRACT

Present situation of arracacha (Arracacia xanthorrhiza) diseases in Brazil

The diseases of arracacha that have already been recorded are described and their current situation in Brazil is discussed. Since its introduction in 1900-1910, arracacha has been considered a nondemanding crop, presenting some minor disease problems, especially when compared to other vegetable crops. Many of the recorded arracacha diseases in Brazil and other Latin American countries are poorly described, for there is hardly any information about pathogenicity tests, pathogen identity, crop losses and environmental conditions affecting diseases. Worldwide, 27 genera of fungi, three of bacteria, nine of nematodes and five species of viruses have been recorded. Of these, thirteen fungi and all bacteria and nematodes were recorded in Brazil. So far, no virus has been recorded, although viruslike symptoms have been observed. The most important diseases are the root knot, caused by Meloidogyne spp., and the postharvest soft rot caused by Erwinia spp. Commonly occurring diseases are leaf spots caused by Septoria spp., Cercospora spp. and Xanthomonas campestris pv. arracaciae, as well as plant rots caused by Sclerotium rolfsii and Sclerotinia sclerotiorum. Viruses could become of great importance since this crop is vegetatively propagated, and part of the plantlets are now being produced in nurseries by a new technique (pre-rooting) and then disseminated to different areas throughout Brazil. As there is no pesticide officially registered for this crop in Brazil, preventive measures of control must be used, such as crop rotation, suitable fertilization and irrigation, and removal and destruction of diseased plants. Arracacha seems to be suitable for organic cropping systems, since few diseases are considered limitant.

Keywords: Arracacia xanthorrhiza, fungi, bacteria, nematodes, virus. 
$\mathrm{U}^{\mathrm{n}}$ m cultivo de mandioquinha-salsa (Arracacia xanthorrhiza Bancroft) dificilmente atingirá o ponto de colheita sem apresentar problemas com algum tipo de doença ou praga devido ao seu ciclo relativamente longo, de 6 até 12 meses. Esta hortaliça é considerada uma cultura rústica, com boa tolerância a doenças e pragas, sendo raros os relatos de perdas severas.

A cultura da mandioquinha-salsa tem aumentado de importância em algumas regiões brasileiras, com incremento da área plantada e do consumo. De acordo com estimativas, em 2000 a área cultivada com mandioquinha-salsa foi de 13.000 ha e uma produtividade média de 9,2 t/ha. O Paraná é atualmente o maior produtor brasileiro, com uma área plantada em 1998 de 7.633 ha, alcançando uma produção de $72.616 \mathrm{t}$ (Santos et al., 2000), seguido por Minas Gerais, com aproximadamente 2.700 ha plantados e 23.700 t colhidas. Outras áreas de produção importantes são a região serrana do Espírito Santo e o planalto norte de Santa Catarina.

$\mathrm{O}$ número de trabalhos de pesquisa publicados sobre a mandioquinha-salsa ainda é relativamente pequeno, apesar de sua importância crescente como opção aos produtores e de seu elevado valor de mercado. Por esta razão, a Embrapa Hortaliças reuniu as informações disponíveis na publicação "Bibliografia Internacional sobre Mandioquinha-Salsa" (Santos et al., 1995). Posteriormente, esta bibliografia foi transformada na "Base de Dados sobre Arracacha/Mandioquinha-Salsa", que conta atualmente com 600 registros que podem ser acessados via internet ( http://www. embrapa.br/bd/ consalsa.html). Destes, foram recuperadas 66 referências sobre doenças em novembro/2000, sendo 20 sobre aspectos gerais da cultura, onde estão incluídas algumas informações sobre enfermidades (Embrapa Hortaliças, 2000).

\section{PATÓGENOS RELATADOS EM MANDIOQUINHA-SALSA NO BRASIL E NO EXTERIOR}

A seguir estão relacionados fungos, bactérias, nematóides e vírus descritos em mandioquinha-salsa, com uma aná- lise crítica das informações dos relatos e comentários sobre a situação das doenças mais importantes nas nossas condições. É possível que outros patógenos já tenham sido registrados para a cultura e sua publicação ignorada, e colaborações e correções são bem-vindas.

\section{FUNGOS}

Foram registrados 27 gêneros de fungos no Brasil, Peru, Colômbia, Venezuela, Bolívia, Equador e Estados Unidos (Tabela 1), e destes apenas treze foram relatados no País. A maior parte dos fungos pode ser considerada de importância secundária como causadores de perdas para cultura. No Brasil, as doenças causadas por fungos constam de listas em revisões sobre doenças da cultura depois de ter sido registrada sua ocorrência ou associação (Reifschneider et al., 1983; Stradiotto, 1995; Lopes \& Henz, 1997; Ventura \& Costa, 1998; Mendes et al., 1998), mas grande parte destes não foi formalmente descrita. No exterior, muitas das doenças causadas por fungos são citadas em artigos genéricos sobre tratos culturais, sem muitos detalhes. Em 1997 foi publicado o livro "Enfermedades fungosas y bacterianas de raíces y tubérculos andinos", por Ames de Icochea, que contém um capítulo sobre doenças de mandioquinha-salsa, com informações mais detalhadas sobre etiologia, epidemiologia e controle.

Os primeiros patógenos relatados como problema no Brasil foram Sclerotium rolfsii e Rosellinia bunodes (Normanha, 1958; Normanha \& Silva, 1963), fungos de solo que afetam as raízes e o colo da planta. Posteriormente também foram incluídos Sclerotinia sclerotiorum e Fusarium spp. (Reifschneider et al., 1983). Na região serrana do Espírito Santo, Sclerotinia sclerotiorum é uma das principais doenças da mandioquinha-salsa (Costa et al., 1987; Ventura \& Costa, 1998). No Paraná, Jaccoud Filho et al. (1999) relataram a ocorrência de perdas significativas devido a Sclerotinia sclerotiorum e Sclerotium rolfsii, entre outros problemas fitossanitários. Atualmente, estes dois fungos continuam sendo os patógenos de solo mais impor- tantes para a cultura, e ocorrem nas regiões produtoras do Espírito Santo, Minas Gerais e Paraná. Nestes estados, a mandioquinha-salsa é cultivada em regiões serranas, com alta umidade relativa durante todo o ano, condição favorável ao desenvolvimento da doença, sendo que $S$. sclerotiorum predomina em temperaturas mais baixas e $S$. rolfsii nas mais altas. Além disto, estes fungos são polífagos e possuem alta capacidade de sobrevivência.

Entre os fungos que atacam a parte aérea da planta, Septoria apii (provável sinônimo de S. apii-graveolentis) e Cercospora arracacina foram identificados na cultura por Viégas (1961), e continuam de ocorrência generalizada no País, causando lesões nas folhas mais velhas, embora não causem grandes perdas. Erysiphe polygoni e Puccinia repentina (Viégas, 1961) não foram mais mencionados em publicações posteriores, podendo ser considerados de importância secundária. Alternaria spp. e Oidium spp. são mencionados como patógenos, mas seu relato não foi formalmente publicado (Santos et al., 1991). O fungo Albugo ipomoeaepanduratae, causador da ferrugem branca, é citado no livro "Fungos em Plantas no Brasil" (Mendes et al., 1998) como patógeno de mandioquinha-salsa, entretanto, os três resumos citados referem-se ao patógeno associado à batata-doce (Fitopatologia Brasileira, v.14, n.2, p.114, p.117 e p.155, julho 1989), devendo ser portanto desconsiderado. Nos países andinos já foram registrados vários fungos ainda não constatados no Brasil (Tabela 1), como Ascochyta spp., Colletotrichum spp., Lasiodiplodia theobromae, Leveillula taurica, Macrophomina phaseolina e Tilletia spp. Na Venezuela, Rhizoctonia spp. foi descrito como um dos problemas mais sérios da cultura (Reyes, 1970), causando mais danos a campo que Erwinia spp. As maiores perdas foram observadas em mudas, raízes e talos das plantas; este fungo também foi registrado na Costa Rica (Subirós, 1984). Frere et al. (1975) mencionam a ocorrência de Rhizoctonia crocorum na região andina, uma espécie pouco comum deste gênero. Fusarium solani foi relatado como patógeno das raízes na Venezuela por Díaz Polanco \& Camino (1976), tanto a 
Tabela 1. Relação de fungos relatados para mandioquinha-salsa no Brasil e no exterior.

\begin{tabular}{|c|c|c|}
\hline Fungos $^{1}$ & País de Ocorrência & Referência \\
\hline Alternariaspp. & Brasil, Peru & $\begin{array}{l}\text { Santos et al. (1991), Ames de Icochea } \\
\text { (1997) }\end{array}$ \\
\hline Ascochyta spp. & Peru & Ames de Icochea (1997) \\
\hline Aspergillus spp. ${ }^{1}$ & Colômbia & Thompson (1980) \\
\hline Botrytis cinerea & EUA & Burton (1970) \\
\hline Cercospora spp. ( C. arracacina) $)^{1}$ & Brasil & Viégas (1961) \\
\hline Cercosporidium depressum ${ }^{1}$ & Venezuela & Reyes (1970) \\
\hline Colletotrichum spp. & Peru, Venezuela & Reyes (1970), Ames de Icochea (1997) \\
\hline Erysiphe polygoni & Brasil & Viégas (1961) \\
\hline $\begin{array}{l}\text { Fusarium spp. (F. solani, } F \text {. } \\
\text { moniliforme, F. oxysporum) }\end{array}$ & EUA, Brasil, Peru & $\begin{array}{l}\text { Burton (1970), Reifschneider et al. } \\
\text { (1983), Ames de Icochea (1997) }\end{array}$ \\
\hline Geotrichum spp. & Brasil & Henz et al. (1994) \\
\hline Lasiodiplodia theobromae & Peru & Ames de Icochea (1997) \\
\hline Leveillula taurica & Peru & Ames de Icochea (1997) \\
\hline Macrophomina phaseolina & Peru & Ames de Icochea (1997) \\
\hline Mucor spp. & EUA, Colômbia, Peru & $\begin{array}{l}\text { Burton (1970), Thompson (1980), Ames } \\
\text { de Icochea (1997) }\end{array}$ \\
\hline Nigrospora spp. ${ }^{1}$ & Colômbia & Thompson (1980) \\
\hline Oidium spp. ${ }^{1}$ & Brasil & Santos et al. (1991) \\
\hline Penicillium spp. & EUA, Colômbia & Burton (1970), Thompson (1980) \\
\hline Phoma spp. ${ }^{1}$ & Brasil & Henz et al. (1994) \\
\hline Puccinia repentina $^{1}$ & Brasil & Viégas (1961) \\
\hline Rhizoctonia spp. ( R. crocorum $)^{1}$ & Venezuela & Reyes (1970) \\
\hline Rhizopus spp. ( R. nigricans) & Brasil, EUA, Peru, Colômbia & $\begin{array}{l}\text { Normanha (1958), Burton (1970), } \\
\text { Thompson (1980), Ames de Icochea } \\
\text { (1997) }\end{array}$ \\
\hline Rosellinia bunodes ${ }^{1}$ & Brasil & Normanha (1958) \\
\hline Sclerotinia sclerotiorum & Brasil, Peru & $\begin{array}{l}\text { Reifschneider et al. (1983), arrantes } \\
\text { (1998) }\end{array}$ \\
\hline Sclerotium rolfsii & Brasil & Normanha (1958) \\
\hline $\begin{array}{l}\text { Septoria (S. apii, S. apii- } \\
\text { graveolentis) }\end{array}$ & Brasil, Peru & Viégas (1961), Ames de Icochea (1997) \\
\hline Syncephalastrum spp. ${ }^{1}$ & Colômbia & Thompson (1980) \\
\hline Tilletia spp. & Peru & Ames de Icochea (1997) \\
\hline
\end{tabular}

${ }^{1}$ A relação de patogenicidade entre o agente causal e a mandioquinha-salsa não foi formalmente caracterizada ou mencionada na publicação.

campo como em pós-colheita, estando associado a Erwinia. Estes autores propuseram uma nova forma specialis (f. sp. arracaciae) para $F$. solani, aparentemente não adotado como um nome válido. $\mathrm{Na}$ Venezuela, é citada a ocorrência de Megacladosporium depressum, um fungo pouco conhecido que é sinônimo de Cercosporidium depressum (Farr et al., 1989), e Gloeosporium spp. (Reyes, 1970), atualmente incorporado ao gênero Colletotrichum.
Na fase de pós-colheita, foram relatados como possíveis causadores de podridões das raízes representantes dos gêneros Aspergillus, Botrytis, Fusarium, Geotrichum, Mucor, Nigrospora, Penicillium, Phoma, Rhizopus e Syncephalastrum (Burton, 1970; Thompson, 1980; Henz et al., 1994; Ames de Icochea, 1997). No Brasil, Rhizopus nigricans já era relatado como problema nos primeiros artigos sobre a cultura (Normanha \& Silva, 1963). Por sua agressividade, Rhizopus e Mucor são os patógenos mais importantes, mas Fusarium e Geotrichum também podem causar perdas consideráveis, especialmente quando ocorrem em infecções mistas com outros fungos e bactérias. Burton (1970) identificou e comprovou a patogenicidade de Botrytis cinerea, Fusarium oxysporum e F. solani, Mucor, Penicillium e Rhizopus em raízes de mandioquinha-salsa importadas de Porto Rico comercializadas no mercado de 
Chicago. Alguns trabalhos publicados sobre doenças de pós-colheita de mandioquinha-salsa incluem Aspergillus, Nigrospora e Syncephalastrum como patogênicos, baseando-se no trabalho de Thompson (1980). O autor apenas identificou estes fungos a partir da água onde as raízes foram lavadas, sem nenhuma menção a provas de patogenicidade, e portanto não deve ser considerado como um relato válido. Em mandioquinha-salsa, estes fungos geralmente estão apenas associados à parte externa das raízes, em lesões causadas por injúrias mecânicas, sem estar diretamente envolvidos na doença, sendo fracamente ou não patogênicos.

Em sementes botânicas de mandioquinha-salsa provenientes do Paraná foram detectados Alternaria, Septoria, Aspergillus e Colletotrichum pelos métodos de papel de filtro e incubação em meio de cultura (BDA), mas não é mencionada a realização de testes de patogenicidade (Menezes \& Fayad, 1998). Estes fungos devem ser considerados como uma associação às sementes.

A determinação taxonômica mais acurada de alguns destes fungos é importante para facilitar o reconhecimento das doenças, determinar o círculo de hospedeiras e medidas adequadas de controle. Para alguns gêneros importantes, como Fusarium, Colletotrichum e Alternaria, falta a denominação específica, e para outros verificar sua validade, como Cercospora arracacina, Septoria (S. apii, S. apii-graveolentis) e Rhizoctonia (R. crocorum). Vários fungos registrados no centro de origem da cultura ainda não foram relatados no Brasil, como Ascochyta spp., Colletotrichum spp., Lasiodiplodia theobromae, Leveillula taurica, Macrophomina phaseolina e Tilletia spp., e desta forma é fundamental a observação das normas quarentenárias no caso de introdução de material genético de países da região andina.

\section{BACTÉRIAS}

Cinco bactérias já foram registradas para a cultura até o momento, pertencentes a três gêneros: Xanthomonas, Erwinia e Pseudomonas (Tabela 2). Em
1971, Pereira et al. relataram a ocorrência de Xanthomonas arracaciae (atualmente X. campestris pv. arracaciae) causando lesões foliares em mandioquinhasalsa no estado de São Paulo, uma nova espécie deste gênero. A denominação comum da doença é queima ou crestamento bacteriano (Pereira et al., 1971; Marques et al., 1994; Oliveira \& Moura, 1995). A espécie foi devidamente reconhecida e listada no "Guide to Plant Pathogenic Bacteria" de Bradbury (1986) como uma nova patovar de X. campestris. Em 1985, Romeiro et al. relataram a ocorrência desta bactéria em Minas Gerais, sendo particularmente destrutiva no verão. Posteriormente, foram estudados outros aspectos, como a caracterização de diversos isolados e a sua atividade bactericinogênica (Romeiro et al., 1988; Siqueira, 1988). O último registro de sua ocorrência foi em Espírito Santo do Pinhal-SP (Paradela et al., 1996), mas aparentemente encontra-se distribuída nas demais regiões produtoras brasileiras (Espírito Santo, Minas Gerais e Distrito Federal), embora ainda não tenha sido formalmente assinalada no Paraná e Santa Catarina.

O primeiro relato da ocorrência de Erwinia em raízes de mandioquinha-salsa foi feito por Burton (1970) nos Estados Unidos, identificando-a somente como gênero. Posteriormente, Camino \& Diaz Polanco (1972a, 1972b) identificaram Erwinia amylovora como o agente causal da murcha e amarelecimento de plantas, necrose foliar e podridão de raízes em campo na Venezuela, e Zapata \& Pardo (1974) identificaram Erwinia spp. na Colômbia, com sintomas similares. Em 1985, Souza et al. relataram a ocorrência de E. carotovora subsp. carotovora em raízes de mandioquinha-salsa em Minas Gerais, no campo e em pós-colheita, em um resumo apresentado no XVIII Congresso Brasileiro de Fitopatologia, realizado em Fortaleza-CE. Este relato foi posteriormente publicado na forma de uma nota na "Plant Pathology" como o primeiro relato da doença e a subespécie carotovora como provável agente causal (Romeiro et al., 1988). Entretanto, existem pelo menos três registros anteriores a este (Camino \& Diaz Polanco, 1972a e 1972b; Zapata \& Pardo, 1974), mesmo que preliminares e incompletos a respeito da identificação bioquímica dos isolados. Estes trabalhos foram provavelmente ignorados por terem sido publicados em revistas de circulação regional da Venezuela e Colômbia e pela identificação incorreta da espécie (E. amylovora). Gomide \& Romeiro (1992) relataram a ocorrência de E. carotovora subsp. carotovora em mandioquinhasalsa no cinturão-verde de Belo Horizonte, na localidade de Floresta. Em trabalhos posteriores, comprovou-se que as principais erwinias pectolíticas (E. carotovora subsp. carotovora, E. c. subsp. atroseptica e E. chrysanthemi) estavam envolvidas nas podridões das raízes (Henz et al., 1992; Marques et al., 1994). Segundo Lopes \& QuezadoSoares (1997), E. carotovora subsp. carotovora é a mais freqüentemente encontrada no Brasil em mandioquinha-salsa. Os surtos de podridão-mole (ou "mela") na fase de pós-colheita em raízes provenientes do Paraná, Minas Gerais e São Paulo no verão são causados majoritariamente por E. chrysanthemi (Henz \& Reifschneider, 2001).

Uma nova bacteriose foliar causada por Pseudomonas cichorii foi descrita por Beriam et al. (1998) no estado de São Paulo, provocando lesões de coloração parda, pequenas e angulares, algumas vezes circundadas por um halo amarelado, principalmente nas folhas baixeiras.

Destas bactérias, as mais importantes são Xanthomonas campestris pv. arracaciae (Xca) e Erwinia spp., que tornam-se problemas no verão, quando predominam temperaturas e umidade elevadas, com chuvas. Xanthomonas ataca principalmente as folhas e pode ser confundida com as lesões causadas por Cercospora e Septoria (Paradela et al., 1996; Lopes \& Quezado-Soares, 1997). Erwinia spp. causa a morte de plantas no campo, em geral associada com ferimentos causados por brocas ou por implementos agrícolas, e também é responsável pela podridão pós-colheita das raízes, ocasionando grandes perdas na fase de comercialização. Erwinia, associada ou não a Rhizopus, também pode causar perdas consideráveis no armazenamento dos fillhotes e redução 
Tabela 2. Relação de bactérias, nematóides e vírus relatados para mandioquinha-salsa no Brasil e no exterior.

\begin{tabular}{|c|c|c|}
\hline Agente Causal/Patógeno ${ }^{1}$ & País de Ocorrência & Referência \\
\hline \multicolumn{3}{|l|}{ Bactérias } \\
\hline Erwinia spp., E. amylovorà & EUA, Colômbia, Venezuela & $\begin{array}{l}\text { Burton (1970), Camino \& Diaz Polanco } \\
\text { (1972a), Zapata \& Pardo (1974) }\end{array}$ \\
\hline $\begin{array}{l}\text { Erwinia carotovorasubs } p \text {. } \\
\text { carotovora }\end{array}$ & Brasil & Souza et al. (1985) \\
\hline E. carotovora.subsp. atroseptica & Brasil & Henz et al. (1994) \\
\hline E. chrysanthemi & Brasil, Peru & $\begin{array}{l}\text { Henz et al. (1994), Ames de Icochea } \\
\text { (1997) }\end{array}$ \\
\hline Pseudomonas cichorii & Brasil & Beriam et al. (1998) \\
\hline $\begin{array}{l}\text { Xanthomonas campestrispv. } \\
\text { arracaciae }\end{array}$ & Brasil & Pereira et al. (1971) \\
\hline
\end{tabular}

\section{Nematóides}

\begin{tabular}{lll} 
Aphelenchoides spp. ${ }^{1}$ & Brasil & Bittencourt et al. (1985) \\
Aphelenchus avenae $^{1}$ & Brasil & Bittencourt et al. (1985) \\
Criconemella spp. (C. onoensis) $^{1}$ & Brasil & Souza et al. (1998) \\
Helicotylenchus spp. (H. dihystera) & ${ }^{1}$ Brasil & Bittencourt et al. (1985), Souza et al. \\
& (1998) \\
Heteroderaspp. ${ }^{1}$ & Brasil & Bittencourt et al. (1985) \\
Hoplolaimus spp. ${ }^{1}$ & Brasil & Bittencourt et al. (1985) \\
Meloidogyne exigua & Brasil & Bittencourt et al. (1985) \\
Meloidogyne hapla & Brasil & Lordello (1970) \\
Meloidogyne incognita & Brasil & Bastos Cruz (1958) \\
Meloidogyne javanica & Brasil & Bittencourt et al. (1985) \\
Pratylenchus spp. & Colômbia & Navarro \& Castaño (1991) \\
Pratylenchus penetrans & Brasil & Monteiro (1980) \\
Pratylenchus coffeae & Brasil & Costa et al. (1998) \\
Tylenchus spp. ${ }^{1}$ & Brasil & Manso et al. (1994), Souza et al. (1998) \\
\hline
\end{tabular}

\section{Vírus}

\begin{tabular}{lll} 
Arracacha virus $A(\mathrm{AVA})$ & Peru & Jones \& Kenten (1978) \\
Arracacha virus $B(\mathrm{AVB})$ & Peru & Kenten \& Jones (1979) \\
Arracacha virus Y(AVY) & Peru & Brunt et al. (2000) \\
Arracacha latent virus(ALV) & Peru & Brunt et al. (2000) \\
Potato black ringspot virus (PBRSV) & Peru & Lizárraga et al. (1994) \\
\hline
\end{tabular}

${ }^{1}$ A relação de patogenicidade entre o agente causal e a mandioquinha-salsa não foi formalmente caracterizada ou mencionada na publicação.

do estande a campo, o que pode ser evitado pela adoção de mudas préenraizadas.

A contaminação e a transmissão de bactérias e outros patógenos através de mudas são componentes epidemiológicos negligenciados atualmente. Parente \& Marques (1990) detectaram Xanthomonas campestris pv. arracaciae e Erwinia spp. em mudas provenientes da Venezuela, sendo interceptadas pelo serviço de quarentena vegetal brasileiro.
Como medida de erradicação destas duas bactérias, as mudas foram tratadas com antibióticos, sendo a cefatoxina sódica o produto mais eficiente nos testes efetuados in vitro.

\section{NEMATÓIDES}

Nove gêneros de nematóides já foram relatados para mandioquinha-salsa (Tabela 2), e todos estão presentes no Brasil. A primeira relação foi publicada em 1985, no "Índice de Doenças de Hortaliças no Brasil - Nematóides" (Bittencourt et al., 1985). Àquela época, já haviam sido registrados sete gêneros no Brasil (Aphelenchoides, Aphelenchus, Helicotylenchus, Heterodera, Hoplolaimus, Meloidogyne, Pratylenchus). Nesta relação foram incluídos registros em que foi descrita uma relação de patogenicidade, desconsiderando-se as referências que descrevem apenas asso- 
ciações. Em outros levantamentos foram acrescentadas as quatro espécies de Meloidogyne (M. exigua, M. hapla, $M$. incognita, $M$. javanica), duas de Pratylenchus (P. penetrans, $P$. coffeae), Criconemella spp. e Tylenchus spp. (Manso et al., 1994; Souza et al., 1998).

Os nematóides causadores das galhas foram o primeiro problema fitopatológico detectado na cultura no Brasil. Na década de 50, na seção de consultas da revista "O Biológico" de São Paulo, Viotti (1954) e Bastos Cruz (1958) responderam a dois agricultores do Estado de São Paulo sobre aspectos da biologia do nematóide e medidas gerais de controle disponíveis àquela época, sendo que na resposta de Bastos Cruz (1958) é mencionada a identificação de $M$. incognita pelo Dr. Jair Carvalho. Posteriormente, a ocorrência de $M$. incognita foi relatada em raízes provenientes de São Paulo e Minas Gerais (Lordello \& Zamith, 1960), e M. hapla em raízes oriundas de Campos do Jordão-SP (Lordello, 1970). Nos municípios de Agudos do Sul e Tijucas do Sul, uma das áreas de produção mais importantes de mandioquinha-salsa do Paraná, foram registradas duas espécies do nematóide das galhas: $M$. incognita e M. hapla (Santos \& Silva, 1984). Até 1995, duas revisões sobre doenças causadas por nematóides em umbelíferas (Ferraz \& Santos, 1984; Huang \& Cares, 1995) só mencionam as três espécies de Meloidogyne ( $M$. javanica, M.javanica e $M$. hapla) como sendo as principais espécies causando perdas em mandioquinha-salsa, embora Bittencourt et al. (1985) também incluam M. exigua. O gênero Meloidogyne também ocorre em mandioquinha-salsa nos países andinos.

A primeira ocorrência de Pratylenchus penetrans em mandioquinha-salsa foi feito por Monteiro (1980) em raízes oriundas de Embú Guaçu-SP. Neste artigo foram incluídas fotos ilustrativas dos sintomas, na forma de lesões rasas, de coloração pardacenta e tamanho variável, desde pequenas manchas até necrose que chega a atingir toda a superfície da raiz. Posteriormente Charchar \& Santos (1997) também relacionaram o gênero Pratylenchus como patógeno da cultura. Na Colômbia, Navarro \& Castaño
(1991) relatam a ocorrência de Pratylenchus spp. no Oriente Antioqueño, a principal região produtora de mandioquinha-salsa, causando manchas pardas de tamanho variável nas raízes, reduzindo seu valor comercial, além de diminuir o tamanho das plantas e de causar amarelecimento da folhagem. Mais recentemente, Costa et al. (1998) identificaram P. coffeae em mandioquinha-salsa no município de Domingos Martins, região serrana do Espírito Santo, com perda total de raízes comerciais em 2,5 ha da cultura, com sintomas na forma de necrose e fendilhamento das raízes.

Os nematóides causadores das galhas continuam sendo uma das principais doenças da cultura, limitando a produção em algumas áreas, com redução da produtividade e da qualidade das raízes, em muitos casos causando elevadas perdas. Afetam a produção de raízes no campo, tornando-as afiladas e sem valor comercial, ou então são descartadas por causa das galhas no beneficiamento. Nestas duas situações as perdas são muito elevadas e podem alcançar até $100 \%$. Pratylenchus spp. pode tornar-se problemático em determinadas regiões pela perda do valor comercial das raízes, e sua importância pode estar subestimada pelo não reconhecimento de seus sintomas e falta de diagnose precisa. Não existem informações suficientes sobre a importância e perdas causadas pelos demais gêneros de nematóides relatados para a cultura, e a relação de patogenicidade e os sintomas em mandioquinha-salsa ainda não foram adequadamente estabelecidos.

\section{VÍRUS}

Cinco vírus foram registrados para a mandioquinha-salsa na região andina (Tabela 2): Arracacha virus A (AVA), Arracacha virus $B$ (AVB), Arracacha virus $Y$ (AVY), Arracacha latent virus (ALV) e o Potato black ringspot virus (PBRSV) (Lizárraga et al., 1994; Hermann, 1997; Brunt et al., 2000). Outros dois vírus (Arracacha virus 2, AV2; e Arracacha virus 3, AV3) foram relatados no Peru, mas sua identificação e validação ainda estão incompletas. O AV2 causa necrose e foi isolado e parcialmente caracterizado (Santa Cruz \& Jayasinghe, 1994), e o AV3 causa subdesenvolvimento e deformação foliar e foi caracterizado como sendo serologicamente relacionado ao Potato virus S(PVS) (Santa Cruz \& Lizárraga, 1997).

Ainda não está muito claro como estes vírus afetam as plantas de mandioquinha-salsa e sua produção (Hermann, 1997), mesmo conhecendose algumas de suas características (Jones \& Kenten, 1978; Jones \& Kenten, 1981; Kenten \& Jones, 1979). Até o momento nenhum destes vírus foi oficialmente registrado em mandioquinha-salsa no Brasil, embora já tenham sido encontradas plantas com sintomas típicos de viroses, como mosaico, nanismo e deformação foliar. Já foram constatadas, através de microscopia eletrônica, inclusões do tipo "catavento", típicas de potyvirus, em tecido foliar de mandioquinha-salsa com sintomas de mosaico cultivadas em Brasília-DF (Elliot W. Kitajima, informação pessoal). A partir de plantas de mandioquinha-salsa com sintomas de virose, transmitiu-se mecanicamente a plantas indicadoras um vírus que está sendo identificado na Embrapa Hortaliças (André N. Dusi, informação pessoal).

Há menções da ocorrência no Brasil de "um vírus do tipo tristeza" em duas referências (Camino \& Díaz Polanco, 1972b; Kay, 1973), cuja fonte foi a "Bibliografia de Raíces y Tubérculos Tropicales", publicada por Montaldo (1967) na Revista de la Facultad de Agronomia de Maracay, Venezuela. Nesta bibliografia consta somente a seguinte informação "COSTA, A.S. e J.T. GRANT. (virus de la tristeza en arracacha). Brasil. 1951", faltando o título e os dados do periódico (nome, volume, páginas). A referência completa pode ser encontrada na lista de viroses publicada por Kitajima (1986), tratando-se de um artigo dos Drs. Álvaro S. Costa e T. J. Grant sobre a transmissão do vírus da tristeza dos citros pelo vetor Aphis citricidus, publicado na Phytopathology (volume 41, número 2, páginas 105-113, 1951). A mandioquinha-salsa, no artigo referida como Arracacha esculenta DC, e plantas de tangelo cv. Sunshine foram usa- 
das apenas para avaliar a retenção do vírus no vetor. Ou seja, os afídeos foram coletados de plantas de citrus infectadas com o vírus, e colocadas nestas duas hospedeiras por períodos de tempo variável (24 a 120 horas), sendo posteriormente transferidos para plantas indicadoras do vírus. No trabalho não é mencionada a infecção de plantas de mandioquinha-salsa pelo vírus. A origem da confusão e da subsequente divulgação errônea desta informação deve ter sido causada pela maneira de citação na bibliografia de Montaldo (1967), e pela falta de acesso ao artigo original de Costa \& Grant (1951) pelos dois autores, que repetiram a informação em suas publicações (Camino \& Díaz Polanco, 1972b; Kay, 1973).

De acordo com Hermann (1997), em mandioquinha-salsa não foi observado o mesmo grau de degeneração causada por viroses que acontece na batata-semente. Entretanto, a exemplo do que ocorre com outras hortaliças propagadas vegetativamente, como alho e batata-doce, plantas de mandioquinha-salsa afetadas por viroses podem apresentar menor desenvolvimento e produção em relação a plantas sadias. Em um futuro próximo, é imprescindível a realização de um levantamento sistematizado de viroses em mandioquinha-salsa no Brasil com técnicas adequadas de detecção. Como a maioria dos vírus é transmitida por mudas, sua identificação é muito importante como medida de controle, evitando-se sua disseminação.

\section{IMPORTÂNCIA DOS REGISTROS DE OCORRÊNCIA PARA A CULTURA}

Os registros de ocorrência de doenças em qualquer espécie de planta são fundamentais para que sejam adotadas medidas de controle adequadas. Além da literatura escassa sobre o tema, muitos dos registros de patógenos em mandioquinha-salsa estão publicados na forma de artigos genéricos em jornais ou revistas técnicas, em periódicos pouco conhecidos ou de pequena circulação. Alguns são relatos "oficiosos" e comunicações preliminares porque fazem menção apenas à associação entre a planta hospedeira e o patógeno. Esta situação foi bem caracterizada por Lopes (1989) na análise de resumos com registros de novas bacterioses em congressos da Sociedade Brasileira de Fitopatologia. Em geral, estes relatos tornam-se definitivos, ou seja, não são publicados posteriormente de forma mais completa como nota ou artigo científico. Como a apresentação em congressos e a conseqüente publicação na forma de resumo é a maneira mais freqüente de relato de ocorrências de doenças, é importante acrescentar um conjunto de informações consideradas como essenciais (Lopes, 1989), tais como: (1) época de observação e constatação da doença; (2) binômio latino da planta hospedeira, importante para a mandioquinha por conta dos vários nomes populares e regionais que possui, onze em português e mais de quinze em espanhol (Hermann, 1997); (3) locais de observação da doença e de coleta de amostras para a identificação do patógeno; (4) perdas reais ou potenciais causadas pela doença; (5) descrição dos sintomas da doença; (6) principais testes utilizados para a caracterização do patógeno; (7) identificação do patógeno em taxons adequados (espécie, subespécie, patovar, etc.); (8) menção da realização dos postulados de Koch; (9) comentários, mesmo que preliminares, sobre a origem da doença; (10) indicação das condições ambientais relacionadas com a ocorrência da doença; (11) informações sobre círculo de hospedeiras ou a reação de cultivares; (12) sugestão de medidas de controle ou linhas de pesquisa neste sentido; (13) disponibilidade de isolados do patógeno em coleções nacionais e internacionais; (14) indicação de que é uma nova doença para a região ou país, ou uma nova hospedeira. Alguns dos relatos de ocorrência de fungos, nematóides e vírus em mandioquinha-salsa não têm validade, e mesmo assim foram perpetuados na literatura como patógenos por publicações posteriores, em que os autores não verificaram atentamente os relatos originais.

Desde 1996, o registro no Brasil de novas pragas - termo que inclui fungos, bactérias, vírus, viróides, nematóides, insetos e ervas daninhas - foi regulamentado através da Portaria $n^{\circ} 290$, publicada no Diário Oficial de 15/04/ 96. Esta portaria interministerial (Ministérios da Agricultura, Pecuária e Abastecimento; da Educação e do Desporto; e da Ciência e Tecnologia) regulamenta a divulgação da ocorrência de qualquer praga inexistente no Território Nacional primeiramente à Secretaria de Defesa Agropecuária (SDA). Em função de sua distribuição, a SDA tomará as providências necessárias para notificar a Organização Mundial de Comércio (OMC), alterar a lista de pragas quarentenárias e liberar a informação. Em termos práticos, os relatos de ocorrência de pragas não existentes no Brasil na forma de artigos ou apresentação em congressos devem obrigatoriamente ser precedidos pela notificação a SDA-Ministério da Agricultura, Pecuária e Abastecimento que depois de analisar a situação permitirá sua divulgação.

\section{MEDIDAS PARA O CONTROLE DE DOENÇAS EM MANDIOQUINHA-SALSA}

Comparada com outras hortaliças, o número de patógenos registrados para a mandioquinha-salsa até o momento pode ser considerado como baixo (Tabelas 1 e 2). Muitos fungos e nematóides registrados são de importância secundária, e a maior parte dos demais patógenos causam problemas localizados. Os mais relevantes têm a relação de patogenicidade e de perdas na produção relativamente bem estabelecidos. A fase de identificação dos patógenos, seu reconhecimento como doenças a campo e a avaliação de prejuízos à produção são fundamentais para se definir estratégias de controle.

A primeira medida de controle a ser considerada para a cultura da mandioquinha-salsa deve ser baseada no princípio de exclusão, prevenindo-se a introdução de patógenos. $\mathrm{O}$ centro de origem da mandioquinha-salsa é a região andina, e parte do material genético para fins de melhoramento no Brasil provém do Equador, Colômbia, Venezuela e Peru. Nestes países ocorrem vários fungos e vírus ainda não registrados no Brasil (Tabelas 1 e 2), e medidas quarentenárias de entrada são importantes para evitar-se a introdução 
de patógenos. Internamente, o intercâmbio de mudas de uma região para outra, principalmente em áreas novas para a cultura, deve ser feita com mais cuidado. A recente produção especializada de mudas pré-enraizadas em viveiros deve ser feita a partir de matrizes isentas de vírus e outros patógenos, já que são comercializadas e transportadas para diferentes regiões produtoras. A transmissão acidental de patógenos através de mudas pode trazer grandes prejuízos para a cultura no País, com redução do seu potencial produtivo e aumento do custo de produção. Na produção tradicional de mudas, o corte dos filhotes serve de porta de entrada para alguns patógenos, como vírus e Rhizopus e/ou Erwinia. Como resultado, podem ocorrer perdas consideráveis de mudas durante o transporte e armazenamento, assim como redução do estande das plantas a campo. O processo de cura do corte nos filhotes dispensa o uso de produtos químicos, sendo recomendados hipoclorito de sódio e cal hidratada apenas para as mudas não curadas (Brune et al., 1996).

O controle químico de doenças em mandioquinha-salsa está limitado até o presente porque não existe nenhum agrotóxico registrado oficialmente para a cultura no Ministério da Agricultura, Pecuária e Abastecimento. É provável que alguns produtores estejam usando herbicidas, inseticidas e bactericidas, registrados para a cenoura e o aipo (ou salsão), hortaliças da mesma família botânica da mandioquinha-salsa. De acordo com um levantamento de resíduos de agrotóxicos em alimentos realizado no período 1987-1992 no estado do Paraná, foi detectado BHC em duas amostras de mandioquinha-salsa (Zandoná \& Zappia, 1993), o que comprova o uso de produtos proibidos em alguns casos. Algumas publicações mais antigas trazem recomendações de produtos químicos, embora não houvesse registro oficial, como fungicidas para o controle de patógenos foliares, como Cercospora, Septoria e Erysiphe, e de solo, como Sclerotium rolfsii e Rosellinia bunodes (Senna Neto, 1976; Cooperativa Agrícola de Cotia, 1980; Embrater, 1982), ou então os mesmos fungicidas indicados para a cenoura (Camargo, 1992). Alguns fungicidas cúpricos (oxicloreto e hidróxido de cobre) também foram recomendados para a mancha foliar causada por $X$. campestris pv. arracaciae (Paradela et $a l ., 1996)$. O uso de solução de cloro e SOPP (ortofenilfenato de sódio) mais DCNA (2,6-dicloro-4-nitroanilina) associados ao uso de cera e de préresfriamento com água gelada apresentaram boa proteção de áreas cortadas das raízes de mandioquinha-salsa contra fungos de pós-colheita (Burton, 1970). A partir da adoção do receituário agronômico em 1988, e por conta de suas conseqüências legais, não foram mais recomendados agrotóxicos para a cultura. No Peru, são indicados alguns produtos químicos para o controle de doenças e pragas, como cúpricos e ditiocarbamatos para o controle de Ascochyta e Septoria (Barrantes, 1998).

É provável que no futuro pelo menos alguns agrotóxicos poderão ser indicados para a mandioquinha, inclusive por extensão de uso. Enquanto isto não ocorre, medidas preventivas de controle devem ser observadas para reduzir a ocorrência de problemas fitossanitários, tais como o uso de mudas com boa qualidade sanitária, de preferência préenraizadas, a adoção de um sistema de rotação de culturas, eliminação de plantas doentes ou suas partes, manejo da irrigação e adubação, entre outras.

A mandioquinha-salsa possui um mercado com boas possibilidades de expansão, e uma reputação de ser um produto saudável, com pouco uso de agrotóxicos, que deve ser preservada e melhor explorada. Também é importante a manutenção da visão positiva de produtores e técnicos, que a consideram uma cultura rústica e tolerante a pragas e doenças, em geral limitantes para outras hortaliças. Parte dos produtores de mandioquinha-salsa utilizam tão poucos insumos químicos (fertilizantes e agrotóxicos) que consideram a cultura “quase orgânica”. Para Souza (1995), é uma das espécies mais promissoras para o cultivo orgânico por sua elevada capacidade de extração de nutrientes do solo e alta resistência a pragas e doenças. De fato, quando adotadas as medidas preventivas, seu cultivo neste sistema é plenamente viável, como atestam os trabalhos realizados no Espírito Santo, onde obteve-se uma produção mé- dia de 17 t/ha no sistema orgânico, superior aos $12 \mathrm{t} /$ ha do sistema convencional (Souza, 1995; Souza, 1998).

A resistência genética para as doenças mais relevantes tem sido pouco explorada na cultura. Aparentemente existem somente três cultivares sendo plantadas no País: uma de raiz branca ('Branca'), e duas de raízes amarelas, a 'Amarela Comum' ou 'Amarela de Carandaí' e 'Amarela de Senador Amaral'. Esta última foi lançada pela Embrapa Hortaliças em 1998, tendo como características principais maior produtividade, precocidade e boa conformação de raízes (Embrapa Hortaliças, 1999). Até o momento, tem sido caracterizada a resistência e feita seleção de clones mais resistentes somente para o nematóide das galhas (Meloidogyne spp.), identificando-se alguns clones de raízes brancas (Charchar \& Santos, 1996) e de raízes amarelas resistentes, entre eles a cv. Amarela de Senador Amaral (Charchar \& Santos, 1999).

Os levantamentos de doenças, seu estudo sistematizado e o registro cuidadoso de novas enfermidades ou surtos nas principais regiões produtoras são muito importantes para manter a sustentabilidade da cultura e continuar sendo uma boa opção de renda, especialmente para os pequenos agricultores. A avaliação de métodos alternativos de controle e a definição das condições predisponentes às doenças são medidas de curto prazo que podem minimizar os impactos dos patógenos na cultura. Os custos de produção da mandioquinhasalsa são menores quando comparados com outras hortaliças, principalmente em relação ao controle de doenças, e para manter esta característica é preciso fazer a diagnose correta das doenças para definir a melhor estratégia de controle entre aquelas disponíveis atualmente.

\section{AGRADECIMENTOS}

Agradeço aos pesquisadores Carlos A. Lopes, André N. Dusi e João M. Charchar (Embrapa Hortaliças, BrasíliaDF) e Francisco J.B. Reifschneider (CGIAR, Washington, EUA) pelas informações, correções e revisão criteriosa deste artigo.

\section{LITERATURA CITADA}

Hortic. bras., v. 20, n. 2, jun. 2002. 
AMES de ICOCHEA, T. Enfermedades fungosas y bacterianas de raices y tubérculos andinos. Lima: CIP, 1997. 172 p.

BARRANTES, F. Patologia de raíces y cormos andinos. In: SEMINARIO, J. (ed.). Producción de raices andinas - manual de capacitación. Lima: CIP, 1998. (Fascículo, 17).

BASTOS CRUZ, B.P. Mandioquinha-salsa com nematóide. O Biológico, São Paulo, v. 24, n. 12, p. $275,1958$.

BERIAM, L.O.S; ALMEIDA, I.M.G.; RODRIGUES NETO, J.; MALAVOLTA JR., V.A. Mandioquinha-salsa, novo hospedeiro de Pseudomonas cichorii. Summa Phytopathologica, São Paulo, v. 24, p. 261-262, 1998.

BITTENCOURT, C.; REIFSCHNEIDER, F.J.B.; CORDEIRO, C.M.T. Índice de doenças de hortaliças no Brasil: nematóides - vol. 3. Brasília: Embrapa/CNPH, 1985. 88 p.

BRADBURY, J.F. Guide to plant pathogenic bacteria. London: CAB/International Mycological Institute, 1986. $332 \mathrm{p}$.

BRUNE, S.; GIORDANO, L.B.; LOPES, C.A.; MELO, P.E. Tratamento químico de mudas de mandioquinha-salsa. Horticultura Brasileira, Brasília, v. 14, n. 2, p. 207-210, 1996.

BRUNT, A.A.; CRABTREE, K.; DALLWITZ, M.J.; GIBBS, A.J., WATSON, L.; ZURCHER, E.J. (eds.). (1996 onwards). Plant viruses online: descriptions and lists from the VIDE database. Version: 20 ${ }^{\text {th }}$ August 1996. URL: http:// image.fs.uidaho.edu/vide). Consultado em 05/08/ 00 .

BURTON, C.L. Diseases of tropical vegetables on the Chicago market. Tropical Agriculture, Trinidad, v. 47, n. 4, p. 303-313, 1970.

CAMARGO, L.S. As hortaliças e seu cultivo. Campinas: Fundação Cargill, 1992. 252 p. (Série Técnica, 6)

CAMINO, J.M.; DÍAZ POLANCO, C Identificación de una bacterioses en apio (Arracacia xanthorrhiza). Agronomia Tropical, Venezuela, n. 22, n. 5, p. 563-567, 1972a.

CAMINO, J.M.; DÍAZ POLANCO, C. Identificación de una bacteriosis en apio. Noticias Tuberosas, Venezuela, n. 2, p. 58, 1972b. Resumo.

CHARCHAR, J.M.; SANTOS, F.F. Resistência de mandioquinha-salsa a nematóides de galhas (Meloidogyne spp.). Horticultura Brasileira, Brasília, v. 14, n. 1, p. 82, 1996.

CHARCHAR, J.M.; SANTOS, F.F. Nematóides em mandioquinha-salsa e seus controles. Informe Agropecuário, Belo Horizonte, v. 19, n. 190, p. 51-53, 1997.

CHARCHAR, J.M.; SANTOS, F.F. Resistência de mandioquinha-salsa a infecção por nematóides das galhas. Horticultura Brasileira, Brasília, v. 17, n. 3, p. 282, 1999.

COOPERATIVA AGRÍCOLA DE COTIA. $M a$ nual de controle de doenças e pragas. São Paulo: CAC-Cooperativa Agrícola de Cotia, 1980. 241 p. COSTA, A.S.; GRANT, T.J. Studies on transmission of the tristeza virus by the vector, Aphis citricidus. Phytopathology, v. 41, n. 2, p. 105-113, 1951.

COSTA, H.; SANTOS, J.M.; VENTURA, J.A.;
ZAMBOLIM, L. Pratylenchus coffeae em mandioquinha-salsa (Arracacia xanthorrhiza) no estado do Espírito Santo. Nematologia Brasileira, v. 22, n. 2, p. 7, 1998. Resumo.

COSTA, H.; VENTURA, J.A.; BALBINO, J.M.S Murcha de Sclerotinia em batata-baroa no estado do Espírito Santo. Fitopatologia Brasileira, Brasília, v. 12, n. 2, p. 123, 1987. Resumo. DÍAZ POLANCO, C.; CAMINO A., J.M. Una nueva forma de Fusarium solani, patógeno del apio (Arracacia xanthorrhiza) en Venezuela. Agronomia Tropical, Venezuela, n. 26, n. 4, p. 353358, 1976.

EMBRAPA HORTALIÇAS. Mandioquinha-salsa "Amarela de Senador Amaral". Disponível: http:/ /www.cnph.embrapa.br/cultivares/ Mandioquinha.html. Consultado em 27/04/99. 4 p. EMBRAPA HORTALIÇAS. Base de dados sobre arracacha/mandioquinha-salsa. Disponível em URL: http://www.embrapa.br/bd/ consalsa.html. Consultado em 10/11/00.

EMBRATER. Sistemas de produção para a cultura da mandioquinha-salsa. Belo Horizonte: Embrater/Embrapa, 1982. 33 p.

FARR, D.J.; BILLS, G.F.; CHAMURIS, G.P.; ROSSMAN, A.Y. Fungi on plants and plant products in the United States. Saint Paul: APS Press, 1989. 1252 p.

FERRAZ, S.; SANTOS, J.M. Os problemas com nematódeos na cultura da cenoura e da mandioquinha-salsa. Informe Agropecuário, Belo Horizonte, v. 10, n. 120, p. 52-57, 1984.

FRERE, M.; RIJKS, J.A.; REA, J. Estudios climatológicos de la zona andina - informe técnico. Roma: FAO, 1975. p. 339-347.

GOMIDE, A.F.; ROMEIRO, R.S. Levantamento de doenças bacterianas em hortaliças na região do cinturão verde de Belo Horizonte. Fitopatologia Brasileira, Brasília, v. 17, n. 1, p. 47-52, 1992.

HENZ, G.P.; LOPES, C.A.; SANTOS, F.F. Doenças pós-colheita de mandioquinha-salsa (Arracacia xanthorrhiza). Horticultura Brasileira, Brasília, v. 10, n. 2, p. 58, 1992.

HENZ, G.P.; LOPES, C.A.; SANTOS, F.F Postharvest diseases of Peruvian carrot (Arracacia xanthorrhiza Bancroft). In: Symposium of the International Society for Tropical Root Crops, 10., 1994, Salvador-BA. Abstracts... Salvador: ISTRC, 1994. p. 65

HENZ, G.P.; REIFSCHNEIDER, F.J.B. Identificação dos agentes causais da podridão-mole da mandioquinha-salsa. Summa Phytopathologica, São Paulo, v. 27, n. 1, p. 106, 2001. Resumo.

HERMANN, M. Arracacha (Arracacia xanthorrhiza Bancroft). In: HERMANN, M.; HELLER, J. (ed.). Andean roots and tubers: ahipa, arracacha, maca and yacón. Roma: IPGRI, 1997. p. $75-172$

HUANG, S.P.; CARES, J.E. Doenças causadas por nematóides em umbelíferas. Informe Agropecuário, Belo Horizonte, v. 17, n. 183, p. 73-79, 1995.

JACCOUD FILHO, D.S.; GARDINGO, J.R.; STABACH, A.R.; CELANO, M.M.; SALVADOR, C.A.; FURIATTI, R.S. Levantamento da ocorrência de doenças na cultura da mandioquinha-salsa (Arracacia xanthorrhiza) na região dos Campos Gerais do Paraná Fitopatologia Brasileira, Brasília, v. 24 (suplemento), p. 292-293, 1999. Resumo.

JONES, R.A.C.; KENTEN, R.H. Arracacha virus
A, a newly recognized virus infecting arracacha (Arracacia xanthorrhiza, Umbelliferae) in the Peruvian Andes. Annals of Applied Biology, v. 90, p. 85-91, 1978.

JONES, R.A.C.; KENTEN, R.H. A strain of arracacha virus B infecting oca (Oxalis tuberosa: Oxalidaceae) in the Peruvian Andes. Phytopathologische Z., v. 100, p. 88-95, 1981.

KAY, D.E. Root Crops. London: TPI, 1973. 245 p. KENTEN, R.H.; JONES, R.A.C. Arracacha virus $\mathrm{B}$, a second isometric virus infecting arracacha (Arracacia xanthorrhiza: Umbelliferae) in the Peruvian Andes. Annals of Applied Biology, v. 93, n. 1, p. 31-36, 1979.

KITAJIMA, E.W. Lista de publicações sobre viroses e enfermidades correlatas de plantas no Brasil (1911-1985). Fitopatologia Brasileira (suplemento), Brasília, 1986. 91 p.

LIZÁRRAGA, C.; CHUQUILLANQUI, C.; JAYASINGHE, U. Una variante del virus del anillo necrótico de la papa ("potato black ringspot virus", PBRV) aislado de arracacha (Arracacia xanthorrhiza). Fitopatología, Lima, v. 29, n. 2, p. 144-149, 1994.

LOPES, C.A. Constatação de novas doenças bacterianas na SBF: fragilidade dos resumos. Fitopatologia Brasileira, Brasília, v. 14, n. 1, p. 5-6, 1989.

LOPES, C.A.; HENZ, G.P. Doenças da mandioquinha-salsa. Informe Agropecuário, Belo Horizonte, v. 19, n. 190, p. 49-51, 1997.

LOPES, C.A.; QUEZADO-SOARES, A.M. Doenças bacterianas das hortalicas: diagnose e controle. Brasília: Embrapa-CNPH / Embrapa-SPI, 1997. $70 \mathrm{p}$.

LORDELLO, L.G.E. ; ZAMITH, A.P.L. Incidência de nematóides em algumas plantas cultivadas de importância econômica. Divulgação Agronômica, v. 2, p. 27-33, 1960.

LORDELLO, L.G.E. Mais um nematóide nocivo à mandioquinha-salsa. Revista de Agricultura, v. 45, n. 1, p. 46, 1970.

MANSO, E.C.; TENENTE, R.C.V.; FERRAZ, L.C.B.; OLIVEIRA, R.S.; MESQUITA, R. Catálogo de nematóides fitoparasitos encontrados associados a diferentes tipos de plantas no Brasil. Brasília: Embrapa/SPI, 488 p. 1994.

MARQUES, A.S.; ROBBS, C.F.; BOITEUX, L.S.; PARENTE, P.M.C. Índice de fitobacterioses assinaladas no Brasil. Brasília: EMBRAPA, 1994. 65 p.

MENDES, M.A.S.; SILVA, V.L.; DIANESE, J.C.; FERREIRA, M.A.S.V.; SANTOS, C.E.N.; NETO, E.G.; URBEN, A.F.; CASTRO, C. Fungos em plantas no Brasil. Brasília: SPI/Embrapa, 1998. 569 p. MENEZES, J.E.; FAYAD, M.G. Detecção de fungos em sementes botânicas de mandioquinha-salsa (Arracacia xanthorrhiza Bancroft) provenientes do Paraná. Horticultura Brasileira, Brasília, v. 16, n. 1, 1998.

MONTALDO, A. Bibliografia de raices y tubérculos tropicales. Maracay: Revista de la Facultad de Agronomia - UCV, 1967. p. 478.

MONTEIRO, A.R. O nematóide Pratylenchus penetrans causa necrose em mandioquinha-salsa no Brasil. In: REUNIÃO BRASILEIRA DE NEMATOLOGIA, 4, 1980, Piracicaba. Anais... Piracicaba: Sociedade Brasileira de Nematologia, 1980. p. 59-60.

NAVARRO, R.; CASTAÑO, J.J. Mancha parda 
de los tubérculos de arracacha. Actualidades ICA, Medellín, v. 5, n. 58, 1991.

NORMANHA, E.S. Mandioquinha-salsa no municipio de Piedade. Campinas: Instituto Agronômico, $1958.5 \mathrm{p}$.

NORMANHA, E.S.; SILVA, J.R. Mandioquinhasalsa tem vários problemas. Coopercotia, v. 20, p. 36-38, 1963.

OLIVEIRA, J.R.; MOURA, A.B.A. Doenças causadas por bactérias em umbelíferas. Informe Agropecuário, Belo Horizonte, v. 17, n. 183, p. 68-69, 1995.

PARADELA, A.L.; MENTEN, J.O.M.; MALAVOLTA JUNIOR, V.A. Mancha foliar em mandioquinha-salsa causada por Xanthomonas campestris pv. arracaciae em Espirito Santo do Pinhal-SP, Brasil. Summa Phytopathologica, Piracicaba, v. 22, n. 1, p. 64, 1996.

PARENTE, P.M.G; MARQUES, A.S.A Suscetibilidade a antibióticos in vitro de Xanthomonas campestris pv. arracaciae e Erwinia carotovora isoladas de batata-baroa (Arracacia xanthorrhiza). Fitopatologia Brasileira, Brasília, v. 15, n. 2, p. 132, 1990. Resumo.

PEREIRA, A.L.G.; PARADELLA FILHO, O.; ZAGATTO, A.G. Uma nova doença bacteriana da mandioquinha-salsa (Arracacia xanthorrhiza) causada por Xanthomonas arracaciae n. sp. Arquivos do Instituto Biológico, São Paulo, v. 38, n. 3, p. 99-108, 1971.

REIFSCHNEIDER, F.J.B.; SIQUEIRA, C.B.; CORDEIRO, C.M.T. Índice de doenças de hortaliças no Brasil: bactérias e fungos - vol. 1 . Brasília: CNPH/EMBRAPA, 1983. 156 p.

REYES Z., V. Apio criollo. Agricultor Venezolano, v. 33 , n. 249 , p. $38-41,1970$.

ROMEIRO, R.S.; SOUZA, R.M.; KIMURA, O.; SOUZA, O.B. Queima bacteriana (Xanthomonas campestris pv. arracaciae) da batata-baroa no estado de Minas Gerais. Fitopatologia Brasileira Brasília, v. 10, n. 2, p. 324, 1985. Resumo. ROMEIRO, R.S.; SOUZA, R.M.; MUCHOVEJ,
J.J.; KIMURA, O. Soft rot of Peruvian carrot due to Erwinia carotovora in Brazil. Plant Pathology, v. 37, n. 2, p. 300-302, 1988.

SANTA CRUZ, M.; JAYASINGHE, U. Aislamiento y caracterización parcial de un virus (AV2) de arracacha (Arracacia xanthorrhiza). Fitopatología, Lima, v. 32, n. 1, p. 9, 1994. Resumo.

SANTA CRUZ, M.; LIZÁRRAGA, C. Un virus serologicamente relacionado com PVS en arracacha (Arracacia xanthorrhiza Bancroft). Fitopatología, Lima, v. 29, n. 1, p. 71, 1997. Resumo.

SANTOS, B.B.; SILVA, L.A.T. Ocorrência de nematóides do gênero Meloidogyne Goeldi 1887 (Nematoda, Heteroderidae) em algumas plantas cultivadas no estado do Paraná, Brasil. Revista de Agricultura, Piracicaba, v. 59, n. 1, p. 21-26, 1984. SANTOS, F.F.; COSTA, G.P.; MACEDO, P.; KRIECK, R.S. Mandioquinha-salsa no agronegócio do estado do Paraná. Curitiba: Emater-PR, 2000. $56 \mathrm{p}$.

SANTOS, F.F.; SPINA, J.B.; LIMA, M.F.B.F Bibliografia internacional de mandioquinha-salsa (Arracacia xanthorrhiza Bancroft). Brasília: Embrapa/CNPH, 1995. 44 p. (Embrapa CNPH. Bibliografia, 02).

SANTOS, F.F.; VIEIRA, J.V.; PEREIRA, A.S.; LOPES, C.A.; CHARCHAR, J.M. Cultivo da mandioquinha-salsa (Arracacia xanthorrhiza Bancroft). Brasília: EMBRAPA-CNPH, 1991. n.p. (EMBRAPA-CNPH. Instruções técnicas, 10).

SENNA NETO, N. Cultura da mandioquinha-salsa. Governador Valadares: PROHORT, 1976. $14 \mathrm{p}$. SIQUEIRA, M.F. Caracterização de Xanthomonas campestris pv. arracaciae, agente etiológico do crestamento da batata-baroa (Arracacia xanthorrhiza). Viçosa: UFV, 1988. 80 p. Tese Mestrado.

SOUZA, J.L. Técnicas de cultivo orgânico em mandioquinha-salsa. In: ENCONTRO NACIONAL SOBRE MANDIOQUINHA-SALSA, 5. 1995, Venda Nova do Imigrante, ES. Palestras e trabalhos técnicos... Venda Nova do Imigrante: SOB, 1995. p. 34-36.

SOUZA, J.L. Agricultura orgânica-tecnologias para a produção de alimentos saudáveis. Vitória: EMCAPA, 1998. 176 p.

SOUZA, J.T. de; CAMPOS, V.P.; MAXIMIANO C. Ocorrência e distribuição de nematóides associados a hortaliças e plantas medicinais. Summa Phytopathologica, Piracicaba, v. 24, n. 3/4, p.283291, 1998.

SOUZA, R.M.; ROMEIRO, R.S.; KIMURA, O Podridão mole (Erwinia carotovora subsp carotovora) da batata-baroa no estado de Minas Gerais. Fitopatologia Brasileira, Brasília, v. 10, n. 2, p. 324, 1985. Resumo.

STRADIOTTO, M.F. Doenças das umbelíferas. Informe Agropecuário, Belo Horizonte, v. 17, n. 183, p. 64-67, 1995.

SUBIRÓS, F. El arracache. In: BIAMONTE, P.; ESCOTO, A.; JIMÉNEZ, R.; STERLING, F.; SUBIRÓS, F. (eds.). Olericultura. San José, Costa Rica: UNED, 1984. p. 301-310.

THOMPSON, A.K. Reduction of losses during the marketing of arracacha (Arracacia xanthorrhiza). Acta Horticulturae, v. 116, p. 5560, 1980.

VENTURA, J.A.; COSTA, H. Doenças da mandioquinha-salsa. In: SANTOS, F.F.; SIMÕES DO CARMO, C.A. (eds.). Mandioquinha-salsa: manejo cultural. Brasília: Embrapa, 1998. p. 5056.

VIÉGAS, A.P. Índice de fungos da América do Sul. Campinas: IAC, 1961. 921 p.

VIOTTI, J. Galhas de nematóide em mandioquinha. O Biológico, São Paulo, v. 20, p. 177-178, 1954.

ZANDONÁ, M.S.; ZAPPIA, V.R.S. Resíduos de agrotóxicos em alimentos: resultado de cinco anos de monitoramento realizado pela Secretaria de Saúde do Paraná. Pesticidas Revista Técnica Cientifica, v. 3, n. 3, p. 49-95, 1993.

ZAPATA G., M.A.; PARDO C., V.M. Estudios sobre el marchitamiento de la arracacha (Arracacia xanthorrhiza) causado por Erwinia sp. Revista Facultad Nacional de Agronomia, v. 29, n. 1, p. 39-42, 1974. 